\title{
Dural Graft-Induced Fibrotic Mass Twelve Years after Successful Treatment of Skull Base Non-Hodgkin Lymphoma Mimicking Recurrence: Case Report and Literature Review
}

\author{
Mario Teo ${ }^{1,2^{*}}$, Sean Martin ${ }^{2}$, James Bowness ${ }^{1}$, Muftah Sam Eljamel ${ }^{1}$ \\ ${ }^{1}$ Department of Neurosurgery, Ninewells Hospital, Dundee, UK \\ ${ }^{2}$ Department of Neurosurgery, Institute of Neurological Science, Glasgow, UK \\ Email: $\underline{\text { marioteo@nhs.net }}$
}

Received October 23, 2013; revised November 23, 2013; accepted December 1, 2013

Copyright (C) 2014 Mario Teo et al. This is an open access article distributed under the Creative Commons Attribution License, which permits unrestricted use, distribution, and reproduction in any medium, provided the original work is properly cited. In accordance of the Creative Commons Attribution License all Copyrights (C) 2014 are reserved for SCIRP and the owner of the intellectual property Mario Teo et al. All Copyright (C) 2014 are guarded by law and by SCIRP as a guardian.

\begin{abstract}
Non-Hodgkin lymphoma involving the skull base is a very rare tumour. The role of surgery for these patients remains controversial, as is the use of dural graft for CSF leak repair. With an increasing incidence of CNS lymphoma, more atypical presentations are reported. It is, therefore, important to include lymphoma in the differential diagnosis of skull base lesions as long-term remission is achievable for such patients, as shown in our case. Dural graft used for CSF leak repair could present with delayed complication mimicking tumour recurrence. Relevant published literature is reviewed.
\end{abstract}

\section{KEYWORDS}

\section{CNS Lymphoma; Skull Base; Dural Graft Repair; Delayed Complication}

\section{Introduction}

Primary central nervous system (CNS) lymphoma is a rare disease and accounts for $1 \%-2 \%$ of intracranial tumours [1,2]. Immunocompromised patients, including those with organ transplantation, congenital immunodeficiencies, and acquired immunodeficiency syndrome (AIDS), are at a particularly high risk of developing this condition. However, there has been an increasing incidence of primary CNS lymphoma among immunologically competent individuals [3].

Skull base primary CNS lymphoma is even rarer, but has been reported [4-6]. In immunocompetent patients with no predisposing history, the disease may not be suspected, since clinically and radiologically, they can be indistinguishable from squamous cell carcinoma, metastases, or intraosseous meningioma. The role of surgery for CNS lymphoma, and more importantly, for skull base

\footnotetext{
"Corresponding author.
}

lymphoma remains controversial as extensive skull base surgery can lead to significant morbidity, and reconstruction is imperative.

We present a case of primary skull base lymphoma, our surgical strategy, long-term outcome and the first reported delayed complication of dural patch in such a patient.

\section{Case Report}

A 49-year-old man initially presented with a 3-week history of persistent right facial pain, which started in the temporomandibular joint and spread to the right maxilla and temple, and was associated with paraesthesia. Two weeks later, he developed right eye ptosis, and visual disturbance. Neurological examination revealed right II, III, IV, V and VI cranial nerve palsies. MRI demonstrated a large destructive lesion in the anterior cranial fossa with breach of the cribriform plate, extension into the ethmoid and sphenoid sinuses, right middle cranial fossa and right 
parapharyngeal space. He subsequently underwent a joint bifrontal craniotomy and transnasal approach for tumour excision, and reconstruction of the anterior cranial fossa floor. Postoperative recovery was initially hindered by persistent CSF leak and pneumocephalus, where he underwent a second procedure for the repair of the CSF fistula using dural substitute (Neuro-Patch synthetic dural substitute, Aesculap).

Subsequent tissue diagnosis confirmed high-grade malignant B-cell lymphoma. Further evaluation (including CT chest, abdomen, pelvis, cerebrospinal fluid (CSF) analysis, serological investigations and bone marrow biopsy) showed no evidence of immunosuppression, of systemic disease, or of other tumours. He was then treated with intravenous chemotherapy (cyclophosphamide, vincristine, doxorubicin, prednisolone), prophylactic intrathecal methotrexate and autologous peripheral blood stem cell transplant. He made an excellent recovery with almost complete resolution of his symptoms. He was followed up regularly for 11 years with no evidence of recurrence.

At 12 years he reported nasal congestion. Surveillance MRI showed a mass lesion with contrast enhancement in the nasopharynx with suprasellar extension (Figure 1). Transnasal biopsy revealed a fibrotic mass secondary to previous dural graft, which was not infected, and did not show any signs of integration with normal tissues. The dural graft was removed with no subsequent CSF leak and complete resolution of the mass and his symptoms. 16 years after his initial diagnosis of skull base lymphoma, he eventually died of causes unrelated to his malignancy.

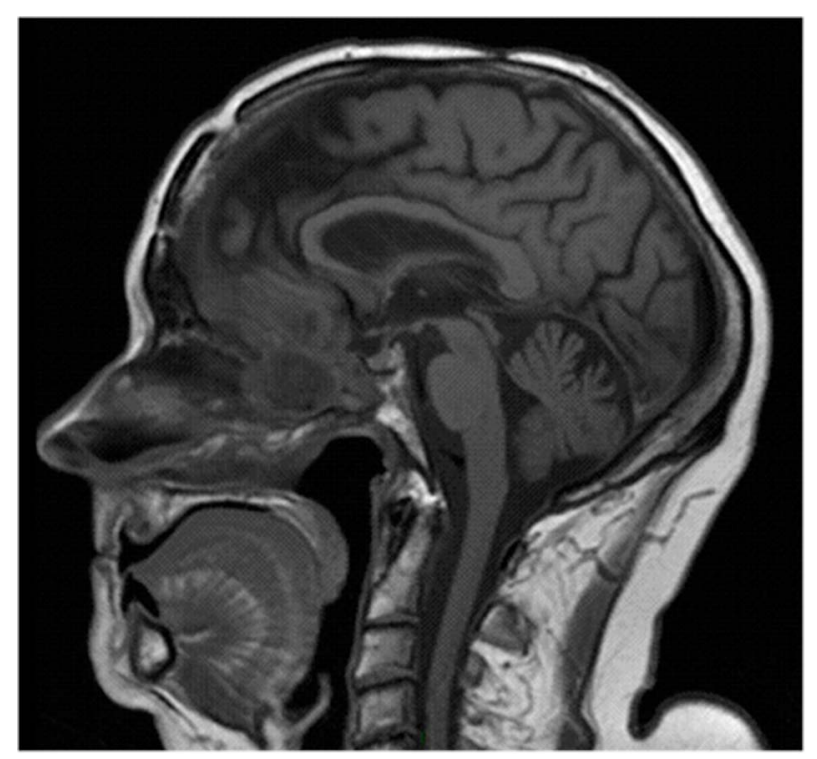

Figure 1. Surveillance MRI (T1 weighted, contrast, sagittal brain) showed a mass lesion with contrast enhancement in the nasopharynx with suprasellar extension, suspicious of recurrent disease.

\section{Discussion}

Lymphoma is characterized by abnormal proliferation of lymphoreticular tissue occurring nodally as Hodgkin's lymphoma or extranodally as non-Hodgkin lymphoma (NHL). CNS lymphoma may occur as a primary disease or as part of disseminated disease. Although lymphomas of the skull base have been classified previously as nonCNS, or extracerebral lymphomas, recent reports described these lesions as atypical intracerebral or primary CNS lymphomas [4,6-8].

CNS lymphomas are uncommon, but the incidence is increasing in both immunocompetent and immunocompromised patients [3]. Historically, the median age of diagnosis of primary CNS lymphoma is 55 years for immunocompetent patients, and 31 years for AIDS patients, though they can occur in all age groups. The male to female ratio is 3:2. They usually occur in the basal ganglia, corpus callosum, thalamus, or periventricular region [9]. As the incidence of CNS lymphoma increases, more atypical presentations of this disease will be encountered.

The differential diagnosis of a destructive lesion in the anterior skull base, as described in this case, includes squamous cell carcinoma arising from the paranasal sinuses, chordoma, metastasis, intraosseous meningioma and esthesioneuroblastoma. Lymphoma, although uncommon, should be included in the differential diagnosis of such neoplasms of the skull base.

Nearly 30 cases of skull base lymphoma have been reported in the literature, with less than 20 reported in adults (Table 1) [4-8,10-13]. Including our patient, adults with skull base lymphoma have a median age of 62 years, and vary from 37 to 83 years. The majority of the patients were male [10], with male to female ratio 5:3. The interval from presentation to diagnosis varied from just over a week to nearly a year. Those with cranial nerve involvement often seek medical attention sooner, as compared to other patients who present late due to raised intracranial pressure symptoms from mass effect.

The initial role of surgery in the management of primary CNS lymphoma is usually tumour biopsy for tissue diagnosis: the role of gross total resection is still controversial, with reports of patients with long-term survival after complete resection of a solitary brain lesion [14,15]. As seen in Table 1, nine patients with skull base lymphoma had tumour biopsy for diagnostic purposes only, and six patients had partial resection of their lesions. We present the only case of gross total resection (curative) of skull base lymphoma with 14 years' survival. Gross total resection was carried out as a primary procedure instead of biopsy, in view of this patient's young age and our understanding of anterior skull base lesions at the time of his initial presentation over a decade ago, extensive skull base surgery was considered the best option for his survival. 
Table 1. Published literature on skull base primary lymphoma published in adult population. Abbreviations: N.A.: not available, SB: sphenoid bone, ES: ethmoid sinus, CS: cavernous sinus, RP: retropharyngeal space, AF: anterior fossa, MF: middle fossa, PF: posterior fossa, Bx: biopsy, PR: partial resection, GTR: gross total resection, RT: radiotherapy, CT: chemotherapy, iv: intravenous, it: intrathecal.

\begin{tabular}{|c|c|c|c|c|c|c|c|c|c|}
\hline & Age & Sex & $\begin{array}{c}\text { Symptom } \\
\text { Interval }\end{array}$ & Pathology & $\begin{array}{c}\text { Involvement } \\
\text { Site }\end{array}$ & Surgery & Treatment & Outcome & Follow Up \\
\hline Oyama et al. 1992 [10] & 62 & M & 4 months & B cell lymphoma & SB, CS & PR & RT, CT & Alive (R) & 5 months \\
\hline Shibata et al. 1992 [11] & 74 & $\mathrm{~F}$ & 10 days & B cell lymphoma & SB, ES, CS & PR & RT, CT & Died & 14 months \\
\hline Tanaka et al. 1994 [12] & 46 & $\mathrm{~F}$ & 3 weeks & B cell lymphoma & SB, CS, & PR & RT, CT & Died & 10 months \\
\hline \multirow[t]{4}{*}{$\begin{array}{l}\text { Roman-Goldstein et al. } \\
1998 \text { [7] }\end{array}$} & 37 & M & N.A. & lymphoma ?type & CS & $\mathrm{Bx}$ & RT, CT & Alive & 4 years \\
\hline & 62 & M & N.A. & lymphoma ?type & CS, SB, ES & $\mathrm{Bx}$ & CT, RT & Died & 18 months \\
\hline & 51 & $\mathrm{~F}$ & N.A. & lymphoma ?type & CS & PR & CT & N.A. & N.A. \\
\hline & 69 & M & N.A. & lymphoma ?type & MF & $\mathrm{Bx}$ & CT & N.A. & N.A. \\
\hline Jaiswal et al. 2000 [8] & 40 & M & 6 months & B cell lymphoma & $\mathrm{PF}, \mathrm{CS}$ & PR & $\mathrm{CT}, \mathrm{RT}$ & Alive & 3 months \\
\hline \multirow[t]{4}{*}{ Dare et al. 2001 [5] } & 64 & $\mathrm{~F}$ & 3 months & B cell lymphoma & SB, ES, CS, MF & $\mathrm{Bx}$ & $\begin{array}{l}\text { RT, CT } \\
\text { (it, iv) }\end{array}$ & Alive & 1 year \\
\hline & 71 & M & N.A. & B cell lymphoma & $\mathrm{SB}, \mathrm{ES}, \mathrm{CS}, \mathrm{AF}$ & $\mathrm{Bx}$ & RT & N.A. & N.A. \\
\hline & 73 & M & N.A. & B cell lymphoma & ES, AF & $\mathrm{Bx}$ & RT & Died & 20 months \\
\hline & 83 & M & N.A. & B cell lymphoma & $\mathrm{ES}, \mathrm{AF}$ & $\mathrm{Bx}$ & RT & Alive & 3 months \\
\hline Tsai et al. 2002 [13] & 60 & $\mathrm{~F}$ & 2 months & B cell lymphoma & SB & PR & CT & N.A. & N.A. \\
\hline Jung et al. 2004 [6] & 56 & $\mathrm{~F}$ & 2 months & B cell lymphoma & SB, CS & $\mathrm{Bx}$ & CT (iv, it) & N.A. & N.A. \\
\hline Hans et al. 2005 [4] & 64 & M & 9 months & B cell lymphoma & SB, ES & $\mathrm{Bx}$ & CT (iv), RT & Alive & 1 year \\
\hline Teo et al. 2013 & 49 & M & 3 weeks & B cell lymphoma & SB, ES, MF, RP & GTR & CT (iv, it) & Died & 16 years \\
\hline
\end{tabular}

The options for treating primary CNS lymphoma have evolved significantly during the last few decades. Radiotherapy and chemotherapy, in isolation or in combination, have significantly increased the survival of many immunocompetent patients with primary CNS lymphoma. Early reports indicated an increase in median survival from 3.3 months to 15.2 months for patients receiving radiotherapy, but with a 5-year survival after treatment of only $7 \%[16,17]$. Patients receiving concomitant chemotherapy and radiotherapy live longer than those receiving radiotherapy alone, with median survival ranges from 16 to 44.5 months; and 5-year survival rate of 20\% - 30\% [1820]. For those with skull base lymphomas, eight patients had chemoradiotherapy, five patients had chemotherapy alone, and three patients had radiotherapy in isolation.

Survival data for patients with skull base lymphoma was available for eleven patients. Four died between 14 months and 20 months. Seven patients were still alive, with our patient having the longest follow up at 14 years. One patient represented at 5 months with recurrent disease, and had further chemoradiotherapy.

As shown in this case, long-term remission can be achieved by aggressive treatment of skull base lymphoma. This patient had a combined transnasal and subfrontal operation for aggressive tumour resection due to both intra- and extracranial tumour components. One of the complicating factors with such aggressive surgical resec- tion of the anterior cranial fossa floor is CSF leak, as was encountered in our patient.

The repair of large dural defects is a problem faced by many neurosurgeons dealing with anterior skull base lesions. Various autografts, allografts, and artificial dural substitutes have been used for some time. Many synthetic plastics and fibres have been used; silastic membranes are some of the more frequently used dural substitutes. This is because they have many advantages for dural repairs: the material is inexpensive, is easily fashioned to size and shape, carries no risk of transmissible disease, and minimally reacts with adjacent neural tissues.

However, the use of silastic dural grafts is not risk free. In 1974 the first case of haemorrhage associated with the used of silastic dural substitute was reported [21], and several reports followed. Cervical myelopathy due to infolding of the dural graft [22], and spinal cord compression [23] due to formation of connective tissue around the silastic grafts were also reported.

Delayed complications occurring after 10 years of silastic dural graft used for cranial surgery were reported in 8 previous cases (Table 2) [24-30]. Among these cases, silastic graft was used in four cases for supratentorial dural repairs, all of which had previous excision of meningioma and overlying dura. When patients presented with neurological symptoms over a decade later, imaging showed a mass lesion at the surgical site, with recurrent 
Table 2. Published literature of delayed complications encountered in patients with intracranial use of silastic dural graft. Abbreviations: PF: posterior fossa, F: frontal, F/T: frontotemporal, P/O: parietooccipital, SAH: subarachnoid haemorrhage.

\begin{tabular}{|c|c|c|c|c|c|c|}
\hline & Age & Sex & $\begin{array}{c}\text { Symptom } \\
\text { Interval (Years) }\end{array}$ & Pathology & Involvement Site & Surgery \\
\hline Simpson et al. 1984 [29] & 15 & M & 10 & Medulloblastoma & $\mathrm{PF}$ & Fibrotic mass \& SAH \\
\hline Simpson et al. 1984 [29] & 22 & M & 10 & Cerebellar astrocytoma & $\mathrm{PF}$ & Fibrotic mass \& SAH \\
\hline Gondo et al. 1991 [27] & 14 & $\mathrm{~F}$ & 11 & Trauma & $\mathrm{PF}$ & Fibrotic haemorrhagic mass \\
\hline Awwad et al. 1991 [25] & 59 & M & 12 & Meningioma & $\mathrm{F}$ & Fibrotic haemorrhagic mass \\
\hline Berrington 1992 [26] & 65 & $\mathrm{~F}$ & 13 & Meningioma & $\mathrm{F} / \mathrm{T}$ & Fibrotic haemorrhagic mass \\
\hline Ohbayashi et al. 1994 [30] & 63 & $\mathrm{~F}$ & 20 & Meningioma & $\mathrm{P} / \mathrm{O}$ & Fibrotic haemorrhagic mass \\
\hline Siccardi et al. 1995 [28] & 53 & M & 10 & Meningioma & $\mathrm{F}$ & Fibrotic haemorrhagic mass \\
\hline Robertson et al. 1997 [24] & 31 & $\mathrm{~F}$ & 14 & Chiari & $\mathrm{PF}$ & Fibrotic haemorrhagic mass \\
\hline Teo et al. 2013 & 61 & M & 12 & Lymphoma & Skull base & Fibrotic mass \\
\hline
\end{tabular}

meningioma being the main differential diagnosis. Intraoperatively, all four cases were found to have a fibrotic haemorrhagic mass associated with the silastic dural graft, and subsequent removal was performed with good postoperative outcome.

The other four patients had silastic dural graft used for posterior fossa repair. The patients presented with headache and vomiting: two patients had cerebellar fibrotic haemorrhagic mass, and the two others had SAH associated with silastic dural graft, to account for their symptoms. All patients subsequently had removal of the silastic dural patch.

We, hereby, report the first case of delayed fibrotic mass associated with synthetic dural graft mimicking tumour recurrence when used in used in skull base reconstruction.

Previous reports have demonstrated that local tissue reaction can lead to the formation of a connective tissue capsule or neomembrane around the silastic graft [31,32]. Due to the inert nature of the silastic graft, adhesions are lacking between the dural substitute and the neomembrane, creating a potential space. Excessive proliferation of dural border cells and prominent sprouting of the delicate capillary network are two characteristics ascribed to these neomembranes $[33,34]$. These sprouting capillaries are fragile and can bleed easily. In addition, there is little support from the surrounding fibrous tissue, making these membranes susceptible to movement, so shearing forces may be generated. Micro or macro haemorrhages can therefore occur into the potential space between the dural graft and the neomembrane.

The presence of neocapillaries around the silastic graft would explain the enhancing nature of such a lesion in our patient, and mimicking a recurrent tumour. Since our patient was symptomatic, and with radiological suspicion of tumour recurrence, he was brought back to theatre. During surgical exploration, the dural graft was clearly not incorporated into the anterior skull base and was eas- ily removed. Despite the removal of the dural substitute, no CSF leak was encountered. Therefore, the silastic graft appears to have provided a platform for the reconstitution of the anterior cranial fossa floor, despite its failure to incorporate into the supporting structure. His symptoms of nasal congestion resolved postoperatively with subsequent follow up imaging showing no evidence of mass lesion.

Another consideration for this case was whether or not we could have performed a tissue biopsy during initial surgery, to make the diagnosis of skull base CNS lymphoma in order to commence the patient on chemoradiotherapy, therefore avoiding CSF leak, anterior skull base repair, and the subsequent delayed dural graft induced complication. As mentioned earlier, in view of his young age and our understanding of anterior skull base lesions at the time of his initial presentation over a decade ago, extensive skull base surgery was considered the best option for his survival. Although it is impossible to draw definite conclusions from a single case, we believe that gross total resection of the tumour has a significant role for the long recurrence-free survival of this patient. Without long-term patient survival, we would not have encountered the subsequent delayed complications as seen in this case.

\section{Conclusions}

With an increasing incidence of CNS lymphoma, more atypical presentations are reported. It is therefore very important to include lymphoma in the differential diagnosis of skull base lesions. The role of surgery in skull base lymphoma is controversial, and we present a patient who had curative gross total resection of the lesion and chemotherapy.

We also report the first case of delayed complications associated with neuro-patch graft used in skull base reconstruction. With the increasing types of synthetic dural substitute available on the market nowadays, we have to 
be vigilant of the potential complications that could be associated, even those occurring over a decade after insertion. Though tumour recurrence remains the main concern for patients with symptoms or radiological suspicion on subsequent follow-up, this case highlights another possibility that we should keep in mind.

\section{REFERENCES}

[1] T. L. Helle, R. H. Britt and T. V. Colby, "Primary Lymphoma of the Central Nervous System: Clinopathological Study of Experience at Stanford," Journal of Neurosurgery, Vol. 60, No. 1, 1984, pp. 94-103. http://dx.doi.org/10.3171/jns.1984.60.1.0094

[2] F. H. Hochberg and D. C. Miller, "Primary Central Nervous System Lymphoma,” Journal of Neurosurgery, Vol. 68, No. 6, 1988, pp. 835-853. http://dx.doi.org/10.3171/jns.1988.68.6.0835

[3] N. L. Eby, S. Gufferman, C. M. Flannelly, S. C. Schold, F. S. Vogel and P. C. Burger, "Increasing Incidence of Primary Brain Lymphoma in the US," Cancer, Vol. 62, No. 11, 1988, pp. 2461-2465.

http://dx.doi.org/10.1002/1097-0142(19881201)62:11<24 61::AID-CNCR2820621135>3.0.CO;2-M

[4] F. J. Hans, M. H. Reinges, K. Nolte, P. Reipke and T. Krings, "Primary Lymphoma of the Skull Base," Neuroradiology, Vol. 47, No. 7, 2005, pp. 539-542. http://dx.doi.org/10.1007/s00234-005-1394-4

[5] O. Dare, R. V. Datta, T. R. Loree, W. L. Hicks and W. Grand, "Sinonasal Non-Hodgkin's Lymphoma with Skull Base Involvement,” Skull Base, Vol. 11, No. 2, 2001, pp. 129-135. http://dx.doi.org/10.1055/s-2001-14433

[6] S. Jung, M. Zimmermann and V. Seifert, "Clivus Lymphoma,” Acta Neurochirurgica, Vol. 146, No. 5, 2004, pp. 533-534. http://dx.doi.org/10.1007/s00701-004-0244-1

[7] S. M. Roman-Goldstein, A. Jones, J. B. Delashaw, S. McMenomey and E. A. Neuwelt, “Atypical Central Nervous System Lymphoma at the Cranial Base: Report of Four Cases," Neurosurgery, Vol. 43, No. 3, 1998, pp. 613-615. http://dx.doi.org/10.1097/00006123-199809000-00119

[8] K. Jaiswal, M. Tripathi, P. S. Chandra, M. C. Sharma and A. K. Maha-patra, "An Unusual Case of Primary Lymphoma of the Skull Base Extending from Cerebellopontine Angle to Cavernous Sinus and Orbit. A Case Report," Journal Neurosurg Science, Vol. 44, No. 3, 2000, pp. 145-148.

[9] J. M. Henry, R. R. Heffner, S. H. Diiard, K. M. Earle and R. L. Davis, "Primary Malignant Lymphomas of the Central Nervous System,” Cancer, Vol. 34, No. 4, 1974, pp. 1293-1302.

http://dx.doi.org/10.1002/1097-0142(197410)34:4<1293:: AID-CNCR2820340441>3.0.CO;2-P

[10] H. Oyama, M. Nagane, S. Shibui, K. Nomura and K. Mukai, "Skull Base Malignant Lymphoma: A Case Report and Review of the Literature," Japanese Journal of Clinical Oncology, Vol. 22, No. 2, 1992, pp. 131-135.

[11] M. Shibata, M. Shimoda and O. Sato, “A Case of Bilateral Panopthalmoplegia Caused by Paranasal Malignant
Lymphoma Extending into the Skull Base,” No Shinkei Geka, Vol. 20, No. 6, 1992, pp. 717-721.

[12] S. Tanaka, H. Nihei, S. Manaka and T. Hori, "A Case of Malignant Lymphoma in the Skull Base," No Shinkei Geka, Vol. 22, No. 1, 1994, pp. 73-78.

[13] V. W. Tsai, L. Rybak, J. Espinosa, M. J. Kuhn, O. W. Kamel, F. Mathews and F. R. Glatz, "Primary B-Cell Lymphoma of the Clivus: Case Report," Surgical Neurology, Vol. 58, No. 3-4, 2002, pp. 246-250. http://dx.doi.org/10.1016/S0090-3019(02)00845-5

[14] K. G. Davies, G. C. Cole and R. D. Weeks, "Twenty Year Survival Following Excision of Primary CNS Lymphoma without Radiation Therapy: Case Report,” British Journal of Neurosurgery, Vol. 8, No. 4, 1994, pp. 487-491. http://dx.doi.org/10.3109/02688699408995120

[15] W. Sonstein, K. Tabaddor and J. F. Ilena, "Solitary Primary CNS Lymphoma: Long Term Survival Following Total Re-section,” Medical Oncology, Vol. 15, No. 1, 1998, pp. 61-65. http://dx.doi.org/10.1007/BF02787347

[16] S. A. Leibel and G. E. Sheline, "Radiation Therapy for Neoplasms of the Brain,” Journal of Neurosurgery, Vol. 66, No. 1, 1987, pp. 1-22. http://dx.doi.org/10.3171/jns.1987.66.1.0001

[17] D. F. Nelson, K. L. Martz, H. Bonner H, J. S. Nelson, J. Newall, H. D. Kerman, J. W. Thomson and K. J. Murray, "Non-Hodgkin's Lymphoma of the Brain: Can High Dose, Large Volume Radiation Therapy Improve Survival? Report on a Prospective Trial by the Radiation Therapy Oncolgy Group (RTOG): RTOG 8315,” International Journal of Radiation Oncology, Biology, Physics, Vol. 23, No. 1, 1992, pp. 9-17. http://dx.doi.org/10.1016/0360-3016(92)90538-S

[18] J. Y. Blay, T. Conroy, C. Chevreau, A. Thyss, N. Quesnel, H. Eghbali, R. Bouabdallah, B. Coiffier, J. P. Wagner, A. Le Mevel, D. Dramais-Marcel, "High-Dose Methotrexate for the Treatment of Primary Cerebral Lymphomas: An Analysis of Survival and Late Neurological Toxicity in a Retrospective Series,” Journal of Clinical Oncology, Vol. 16, No. 3, 1998, pp. 864-871.

[19] M. Brada, D. Dearnaley, A. Horwich and H. J. G. Bloom, "Management of Primary Cerebral Lymphoma with Initial Chemotherapy: Preliminary Results and Comparison with Patients Treated with Radiotherapy Alone,” International Journal Radiation, Oncology, Biology, Physics, Vol. 18, No. 4, 1990, pp. 787-792. http://dx.doi.org/10.1016/0360-3016(90)90398-4

[20] L. M. DeAngelis, J. Yahalom, H. Thaler and U. Kher, "Combined Modality Therapy for Primary CNS Lymphoma,” Journal of Clinical Oncology, Vol. 10, No. 4, 1992, pp. 635-643.

[21] T. Banerjee, J. N. Mergher and W. E. Hunt, "Unusual Complications with use of Silastic Dural Substitute,” The American Surgeon, Vol. 40, No. 7, 1974, pp. 434-437.

[22] W. S. Fisher and E. G. Six, "Cervical Myelopathy from Dural Substitute,” Neurosurgery, Vol. 13, No. 6, 1983, pp. 715-716. http://dx.doi.org/10.1227/00006123-198312000-00020

[23] J. T. Keller, C. M. Ongkiko, M. C. Saunders, F. H. Mayfield and S. B. Dunsker, "Repair of Spinal Defects: An 
Experimental Study,” Journal of Neurosurgery, Vol. 60, No. 5, 1984, pp. 1022-1028.

http://dx.doi.org/10.3171/jns.1984.60.5.1022

[24] S. Robertson and A. Menezes, "Hemorrhagic Complications in Association with Silastic Dural Substitute: Pediatric and Adult Case Reports with a Review of the Literature,” Neurosurgery, Vol. 40, No. 1, 1997, pp. 201206.

[25] E. E. Awwad, K. R. Smith Jr., D. S. Martin and A. Manepalli A, "Unusual Hemorrhage with Use of Synthetic Dural Substitute: MR findings,” Journal of Computer Assisted Tomography, Vol. 15, No. 4, 1991, pp. 618-620. http://dx.doi.org/10.1097/00004728-199107000-00017

[26] N. R. Berrington, “Acute Extradural Hematoma Associated with Silastic Dural Substitute: Case Report,” Surgical Neurology, Vol. 38, No. 6, 1992, pp. 469-470. http://dx.doi.org/10.1016/0090-3019(92)90117-6

[27] G. Gondo, S. Nakayama, Y. Mochimatsu, F. Nakajima and A. Hasegawa, "Posterior Fossa Hemorrhage 11 Years after the Use of Silastic Dural Substitute: Case Report," No Shinkei Geka, Vol. 19, No. 1, 1991, pp. 59-62.

[28] D. Siccardi and A. Ventimiglia, "Fibrotic-Haemorrhagic Reaction to Synthetic Dural Substitute," Acta Neurochirurgica, Vol. 132, No. 1-3, 1995, pp. 148-149. http://dx.doi.org/10.1007/BF01404864

[29] D. Simpson and A. Robson, "Recurrent Subarachnoid
Bleeding in Association with Dural Substitute: Report of Three Cases," Journal of Neurosurgery, Vol. 60, No. 2, 1984, pp. 408-409. http://dx.doi.org/10.3171/jns.1984.60.2.0408

[30] N. Ohbayashi, T. Inagawa, Y. Katoh, K. Kumano, R. Nagasako and H. Hada, "Complication of Silastic Dural Substitute 20 Years after Dural Plasty,” Surgical Neurology, Vol. 41, No. 4, 1994, pp. 338-341. http://dx.doi.org/10.1016/0090-3019(94)90187-2

[31] R. Cohen, S. Aleksic and J. Ransohoff, "Inflammatory Reaction to Synthetic Dural Substitute: Case Report," Journal of Neurosurgery, Vol. 70, No. 4, 1989, pp. 633-635. http://dx.doi.org/10.3171/jns.1989.70.4.0633

[32] R. L. Friede and W. Schachenmayr, "The Origin of Subdural Neomembranes: II-Fine Structures of Neomembranes,” pp. 69-84.

[33] W. Schachenmayr and R. L. Friede, "The Origin of Subdural Neomembranes: I-Fine Structures of the Dura-arachnoid Interface in Man,” American Journal of Pathology, Vol. 92, No. 1, 1978, pp. 53-68.

[34] G. I. Schoefl, "Studies in Inflammation: III-Growing Capillaries: Their Structure and Permeability,” Virchows Archiv für pathologische Anatomie und Physiologie und für klinische Medizin, Vol. 337, No. 2, 1963, pp. 97-141. http://dx.doi.org/10.1007/BF00963592 